\title{
Gesellschaftsberichte
}

\section{Primarius-Prof.-Dr.-Paul-Drobec-Posterpreis 2006}

Hiermit wird der Primarius-Prof--Dr.-Paul-Drobec-Posterpreis ausgeschrieben. Dieser Preis wird alljährlich während der Jahrestagung der ÖOG verliehen. Alle bei dieser Jahrestagung eingereichten Posterbeiträge nehmen an der Auswertung für diese Preisverleihung teil. Es wird jeweils ein Preis für die beste inhaltliche Darstellung und ein Preis für die beste grafische Gestaltung vergeben. Die vier Vorsitzenden der einzelnen Themengruppen bei der Präsentation der Posterbeiträge bilden die Jury, die über die Vergabe des Preises entscheidet. Die Vorstellung der Preisträger und die Überreichung der Preise erfolgt dann zu Beginn der letzten wissenschaftlichen Sitzung der Jakrestagung.

Die Preisgelder stammen aus einem von Prim. Prof. Dr. Paul Drobec im Jahre 2000 dotierten Stiftungsvermögen, dessen Zinserträge jährlich zur Auszahlung gelangen.

\section{Forschungsförderungspreis 2006 der Croma Pharma GmbH}

Die Croma Pharma setzt einen Förderungspreis für eine bedeutende wissenschaftliche Arbeit auf dem Gebiet der Augenheilkunde in der Höhe von $€ \mathbf{3 . 5 0 0},-$ aus.

\section{Teilnahmebedingungen:}

1. Die Bewerber müssen das medizinische Hochschulstudium erfolgreich abgeschlossen haben, die österreichische Staatsbürgerschaft besitzen und dürfen zum Zeitpunkt des Stichtages (siehe Punkt 2.) das 45. Lebensjahr noch nicht vollendet haben; sie dürfen weder Abteilungsleiter noch Klinikchef sein.

2. Die eingereichte Arbeit muss in Maschinschrift hergestellt sein; sie darf jedoch bereits innerhalb der letzten 2 Jahre publiziert worden sein. Die Arbeit muss bis spätestens

\section{Februar 2006}

bei der Österreichischen Ophthalmologischen Gesellschaft, Schlösselgasse 9, 1080 Wien, unter Hinweis auf die Bewerbung zum "Croma Pharma-Förderungspreis" in einem verschlossenen Umschlag einlangen. Der Arbeit ist ein kurzer Lebenslauf des Verfassers beizulegen. Die Einreichung wird vertraulich behandelt.

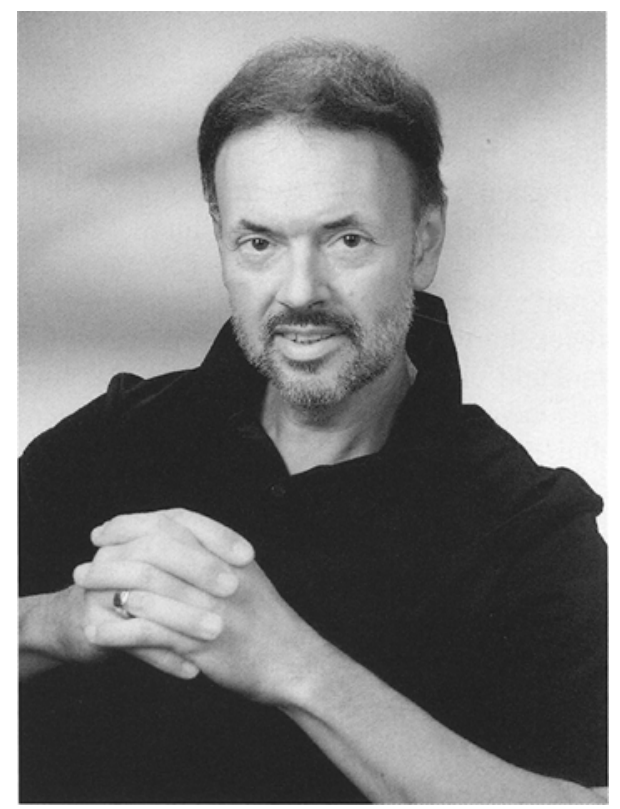

3. Über die Zuerkennung des Preises entscheidet eine Jury der Österreichischen Ophthalmologischen Gesellschaft. Bei gleichwertigen Arbeiten ist den praxisbezogenen der Vorzug zu geben.

4. Die Jury ist berechtigt, den Preis auf mehrere Verfasser zu verteilen; sie kann aber auch von der Zuerkennung des Preises absehen, wenn sie zur Überzeugung gelangt, dass keine preiswürdige Arbeit vorliegt.

5. Die Jury entscheidet mit einfacher Stimmenmehrheit. Ihre Entscheidung ist endgültig und unterliegt keineriei Anfechtung, insbesondere auch nicht vor Gericht.

6. Die Croma Pharma ist berechtigt, den Inhalt der Arbeiten von Preisträgern im Rahmen der Aktivitäten der Croma Pharma zu verwerten, diese ganz - oder teilweise - zu veröffentlichen und Preisträger einzuladen, über das Thema ihrer Arbeit einen Vortrag zu halten.

7. Die gekürten Arbeiten werden im Spektrum der Augenheilkunde veröffentlicht.

8. Der Preis wird anlässlich der ÖOG im Stift Göttweig, 19. bis 21. Mai 2006, von Herrn Mag. pharm. Gerhard Prinz, Gründer und Geschäftsführer der Croma Pharma, persönlich überreicht. 